NBER WORKING PAPER SERIES

\title{
OVERCOMING INFORMATIONAL BARRIERS \\ TO INTERNATIONAL RESOURCE \\ ALLOCATION: PRICES AND GROUP TIES
}

\author{
James E. Rauch \\ Alessandra Casella \\ Working Paper 6628 \\ http://www.nber.org/papers/w6628
NATIONAL BUREAU OF ECONOMIC RESEARCH
1050 Massachusetts Avenue
Cambridge, MA 02138
June 1998

Both authors are affiliated with the NBER (and Casella with the CEPR). Financial support was provided by NSF grant \#SBR-9709237 through the NBER. We thank Vitor Trindade for outstanding research assistance, and seminar participants at Russell Sage Foundation, NYU, Columbia, the Federal Reserve Bank of New York, the NBER, UCLA, and Northwestern for helpful comments. The paper was written while Casella was a Visiting Scholar at the Russell Sage Foundation, whose support and hospitality are acknowledge with gratitude. Initial work on the project was made possible by UCSD through its Distinguished Visitor program. Any opinions expressed are those of the author and not those of the National Bureau of Economic Research.

(C) 1998 by James E. Rauch and Alessandra Casella. All rights reserved. Short sections of text, not to exceed two paragraphs, may be quoted without explicit permission provided that full credit, including (C) notice, is given to the source. 
Overcoming Informational Barriers to

International Resource Allocation:

Prices and Group Ties

James E. Rauch and Alessandra Casella

NBER Working Paper No. 6628

June 1998

JEL No. F10

\section{ABSTRACT}

Incomplete information in the international market creates difficulty in matching agents with productive opportunities and interferes with the ability of prices to allocate scarce resources across countries. Resource-price differentials may not be eliminated and domestic resource supplies may have excessive influence on domestic resource prices. Information-sharing networks among internationally dispersed ethnic minorities or business groups can improve the allocation of resources, though at the same time they may hurt those excluded from the preferential information channels. However, when ties are denser between countries with small resource price differences than between countries with large resource price differences, such networks can worsen the allocation of resources and reduce the value of world output.

James E. Rauch

Department of Economics

University of California, San Diego

La Jolla, CA 92093

and NBER
Alessandra Casella

Department of Economics

Columbia University

New York, NY 10027

and NBER 


\section{Introduction}

International markets do not seem to work very well. Countries appear to trade too much with themselves (e.g., McCallum 1995) and invest too much in themselves (e.g., Feldstein and Horioka 1980). Cross-border price differentials seem too large (e.g., Engel and Rogers 1996).

We take the position in this paper that incomplete information is a major obstacle to the productive operation of international markets. We model incomplete information as a barrier to efficient international matching: it is more difficult in the international than in the domestic market for producers to find the right distributors for their consumer goods, for assemblers to find the right suppliers for their components, for investing firms to find the right partners for their joint ventures, and so on. ${ }^{1}$ Our position is consistent with work showing that empirically identifiable information-sharing networks increase the volume of international trade. Such evidence has been found for business groups ${ }^{2}$ operating across national borders (e.g., Head and Ries 1998), immigrants (e.g., Gould 1994), and long-settled ethnic minorities that maintain coethnic business societies, such as the Overseas Chinese (Rauch and Trindade 1998). Gould (1994) and Rauch and Trindade (1998) find that these groups have less effect on trade in more homogeneous products, for which prices can effectively convey the relevant information, than on trade in more differentiated products, for which matching of multifarious characteristics of buyers and sellers is

\footnotetext{
'Gordon and Bovenberg (1996) also argue that incomplete (in their case, asymmetric) information is a major cause of international immobility of capital.

${ }^{2}$ Business groups are "sets of firms that are integrated neither completely nor barely at all" (Granovetter 1994, p. 455), and where the lineages of the members can often be traced back to a founding family or small number of allied families. Typical mechanisms serving to integrate the firms include mutual stockholdings and frequent meetings of top executives. Business groups are common throughout Asia, continental Europe, and Latin America, but are rare to non-existent in Great Britain and the United States.
} 
more important.

Our major concern is with the impact of incomplete information and group ties on the ability of prices to efficiently allocate scarce resources internationally. In our model production takes place as follows: producers match pairwise, and if the match is acceptable an internationally immobile resource ("labor") is employed to realize the productive opportunity. Domestic matching is characterized by complete information--every producer knows the type of every other--while international matching is hampered by incomplete information: because producers' types are not observable to foreigners, matching is effectively random. However, each producer has access only to the labor in his own country, so domestic matches must employ domestic labor while international matches can employ labor in whichever country it is cheaper. International matches can thus serve to transfer labor demand from the country where labor is scarce to where it is abundant: the price system at work.

We will show that in our model the informational barrier acts like a tax on trade that is zero up to a certain trade volume, then increasing with volume. Full efficiency is therefore achieved between countries whose labor-producer endowment ratios are similar enough, because even with random matching there are enough good matches to transfer sufficient labor demand to equalize wages. If the two countries' endowment ratios are different enough, however, sufficient labor demand to equalize wages cannot be transferred unless some bad matches are accepted, but such matches are only acceptable in the presence of gains from trade created by an equilibrium wage differential. The more different are the labor-producer endowment ratios, the worse is the marginal match and the greater this equilibrium wage differential must be. When wages are not equalized, the comparative statics of the model have the property that an increase in one country's 
labor endowment decreases both its wage and that of its trading partner, but decreases its own wage more. We can call this property "excess sensitivity" from the point of view of the country whose endowment has changed and "partial insulation" from the point of view of its trading partner.

We then enrich our model by including group ties. Group ties extend complete information to the international market: each group member knows the types of all other group members in both countries. This facilitates the transfer of labor demand and increases the extent to which factor endowment ratios can differ without ruling out achievement of full efficiency. In this respect group ties act like an improvement in the matching technology between countries. Group ties differ from such an improvement, however, in that they only overcome informational barriers within the group. When full efficiency is not achieved we can therefore expect the ties to have distributional effects, and in fact we find that they may cause aggregate profits of producers who are not members of the group to fall even though world wages and world profits as a whole increase. Moreover, although ties must reinforce the allocative effect of prices in a two-country model, this need not be true if there is more than one international market so that ties do not necessarily link the countries with the largest difference in factor endowment ratios. We thus conclude the paper with the demonstration that in a three-country model ties can have an effect analogous to harmful "trade diversion," thereby reducing world income. It is the limitations of prices and ties that may place us in the world of the second best: prices convey incomplete information to the complete set of producers while ties convey complete information to an incomplete set of producers.

In the next section of this paper we present our basic model. The equilibrium with 
complete information in all markets is derived in section III, and in section IV we analyze the solution when producers have incomplete information about potential foreign matches. Group ties are introduced in section $V$, and their effects in a three-country model are examined in section VI. Section VII concludes.

\section{The Basic Model}

We begin by describing our basic model in the absence of group ties. The model is constructed with two goals in mind. First, we need a simple general equilibrium set-up where the difference in information between domestic and international partnerships can be captured intuitively and be analytically tractable. Second, we want to include an immobile factor, whose different distribution across countries is the origin of gains from trade, as in traditional analyses.

The world is composed of two countries. In each country, there are two sets of agents: workers and producers. Workers are homogeneous, but their number differs across the two countries: there are $L$ workers in the home country, and $L^{*}$ in the foreign country, where $L>L^{*}$. Producers on the other hand are of different types: in each country a continuum of them is distributed uniformly over a line that extends between -1 and 1. Type $i$ is at location $z_{i}$, representing the producer's type. There is an equal mass, 2 , of producers in both countries. The difference between labor-producer endowment ratios across countries can therefore be summarized by the ratio $L / L^{*}$. In all that follows, asterisks will be used to indicate foreign variables.

Output is generated through a joint venture of two producers, and the distance between their locations on the line is an index of the gains from trade that result from their matching. To 
actively engage in production, a partnership needs to hire labor; thus output is a function of the quality of the producers' match and the labor employed:

$$
y_{i j}=F\left(x, z_{i j}\right)
$$

where $z_{i j}$ is the Euclidean distance between the two producers of types $i$ and $j$, and $x$ is labor. The function $F$ is characterized by constant returns to scale. Producers want to maximize profits.

Two features of this matching technology should be noted at the outset. First, in order to achieve maximum output it is necessary that all matches that are concluded be formed between producers on opposite sides of zero, so that the sum of all producers' distances from zero is contributed to production. It will thus be convenient, when we analyze matching with incomplete information in section IV, to call matches between producers on opposite sides of zero "good matches" and matches between producers on the same side of zero "bad matches." Second, producers differ in their average desirability as match partners, with producers farther from zero tending to be more desirable. This will be especially important when we introduce group ties in sections V and VI, because it will allow group members to differ in their decisions whether to use their ties when matching internationally.

Each producer has the option of matching with a domestic partner, or of entering the international market. In the domestic market there is complete information: everybody knows all others' types and everybody can approach any prospective partner. In equilibrium, competition for desirable partners determines the share of output that goes to each member of the match. All domestic partnerships employ domestic labor.

Alternatively, a producer can enter the international market, where he will match with a foreign producer, similarly interested in an international partnership, and where the two partners 
can choose which of the two countries' labor to employ. Entry to the international market is costless--we want to abstract from traditional trade barriers such as taxes and transport costs in order to isolate the effects of informational barriers. In the international market, information is incomplete: until the match is established and information exchanged, a foreign producer can be of any type with equal probability. Once a partnership is formed and information about types is revealed, ${ }^{3}$ each partner has the option of returning to his home market. Thus only matches yielding profits equal at least to the sum of what the two producers can obtain at home will be concluded, and we assume that any net surplus is then divided equally. In other words, total profits are shared between the two partners according to the Nash bargaining solution, where domestic profits constitute the threat points. Because the option of returning home at no cost is always available, we study equilibria where all producers attempt the international market.

The timing of the model is the following. First, producers go to the international market where partnerships are formed; then information about one's partner is revealed, successful matches are confirmed and unsuccessful ones are broken; finally producers who have rejected their international matches return home and establish new partnerships. The labor markets clear when all demands for labor, from domestic and international ventures, are received. In the resulting equlibrium, international trade consists of flows of producer ("managerial") services in exchange for flows of output.

As discussed at greater length in a companion paper (Casella and Rauch 1997), our model can be read as an assignment problem: different producers must meet and they are not equally

\footnotetext{
${ }^{3}$ We assume that a producer cannot successfully deceive his prospective partner through falsified books, faked product demos, etc.
} 
well-suited to one another (Becker, 1973; Mortensen, 1988; Sattinger, 1993). In domestic partnerships, there is no information problem, and equilibrium matches will correspond to the complete information solution of the assignment model. In international partnerships, on the contrary, each other's type cannot be observed before matching, a scenario equivalent to the incomplete information assignment problem without resampling.

\section{Complete Information}

Because the focus of this paper is on the impact of informational barriers on trade, it is important to establish as a benchmark how our world would fare in the absence of such barriers.

With a constant returns to scale production function, total profits from the match of types $i$ and $j$ can be written as:

$$
\Pi_{i j}=z_{i j} \pi(w)
$$

where $w$ is the wage paid to labor employed by the partnership, and the function $\pi(w)$ is decreasing and convex in $w$. For ease of later proofs, let us also assume that $\pi(w)$ is a constant elasticity function (as would be the case, for example, if the technology were Cobb-Douglas).

Any individual partnership considers the wage constant, and thus joint profits are simply proportional to the distance between the two producers' types. When choosing a partner, each type will want to match with someone on the opposite side of zero, and as close as possible to the outer edge of the distribution. But at the same time, competing for the more desirable partners requires renouncing a larger share of total profits. Proposition 1, established in a general setting, determines individual equilibrium returns in the complete information matching game:

Proposition 1. Consider a contimuum of types distributed on a line. Call $\left\|\mathrm{z}_{\mathrm{i}}\right\|$ type i's distance 
from the median and $\mathrm{z}_{\mathrm{ij}}$ the distance between types $\mathrm{i}$ and $\mathrm{j}$. If the matching of $\mathrm{i}$ and $\mathrm{j}$ results in total profit $\mathrm{C}_{\mathrm{ij}}$, where $\mathrm{C}$ is a positive constant, and each type is free to choose and bid for any matching partner, then in equilibrium type i's return $\mathrm{r}(\mathrm{i})$ will equal $\mathrm{C}\left\|\mathrm{z}_{\mathrm{i}}\right\|$. (The proof is in the Appendix.)

Thus in equilibrium all matches will be formed by partners on the opposite side of the median, and each type can only guarantee for himself a return equal to his net contribution to total profits. Complete information leads to competition, and competition to the disappearance of all "extra" returns. Notice that the proposition cannot predict which matches will take place, but only that all matches must be between two types on opposite sides of the median (generating total returns equal to $\left.\left(\left\|z_{i}\right\|+\left\|z_{j}\right\|\right)\right)$. Because individual returns are determined uniquely, the indeterminacy of the matches is irrelevant.

Proposition 1 can be applied directly to the integrated world economy (IWE), in which complete information prevails in a unified "domestic" market and the distribution of types is uniform with mean and median zero. Type $i$ 's return is given by:

$$
r(i)=\left|z_{i}\right| \pi(w)
$$

where $\left|z_{i}\right|$ is type $i$ 's distance from zero. Since the mass of producers equals 4 , aggregate profits are:

$$
\Pi=\pi(w) 4 \int_{0}^{1} z_{i} d z_{i}=2 \pi(w)
$$

and labor demand:

$$
L^{d}=-2 \pi^{\prime}(w)
$$

where the prime sign indicates the first derivative. Equating labor demand to aggregate labor supply $L+L^{*}$ yields the equilibrium wage $W$. Note that world output is maximized in the IWE.

Consider now a world formed by two countries, each of which has a separate distribution 
of producers' types and a separate labor market. Even when information in the international market is complete, we need to take into account that the set of all potential partnerships is limited by the constraint that the two partners must belong to different countries. In general, this introduces a source of indeterminacy: while the relative profits of all types belonging to any one country are pinned down by the matching game, the relative profits of producers of equal type across the two countries are not. ${ }^{4}$ In our case, however, the existence of an outside option eliminates the problem. As we show in the Appendix, the possibility of reverting to domestic production guarantees that in the presence of complete information and free trade the model has a unique equilibrium: wages must be equalized across countries, and equal type producers must fare equally. We can state:

Proposition 2. If producers have complete information about both domestic and foreign types, then the equilibrium replicates the integrated world economy. (The proof is in the Appendix).

If complete information characterizes both domestic and international matches, the equilibrium replicates the first best. The result is important because it makes clear that any deviation from optimality in the analysis that follows can be attributed to the informational barriers preventing efficient matching in international ventures.

\section{Trade with Incomplete Information}

\section{A. Equilibrium}

When producers have incomplete information about foreign types, international matches

\footnotetext{
${ }^{4}$ This indeterminacy result is well-known in the assignment problem literature; all that can be established is that all home types agree on the welfare ranking of all equilibria; so do all foreign types, and the rankings of the two groups are opposite (Gale and Shapley, 1962).
} 
are effectively random. However, when types are revealed, both producers have the option of returning home. Evaluation of this option requires forming expectations on what returns would be in the domestic markets. This may appear a rather daunting task, because in general returns should depend on the distribution of producers who choose to go back to the domestic market, itself of course a function of expected returns: multiple equilibria seem very likely. Fortunately, the difficulty is limited: Proposition 1 allows us to state that in the complete information matching that characterizes the domestic market, equilibrium returns are independent of the distribution of types present on the market as long as the median of the distribution is unique. This last qualification is necessary because equilibrium returns are defined with respect to distance from the median: if the distribution of types has a gap in the immediate neighborhood of the median, any point in that gap can be interpreted as a median itself, and can provide the anchor against which equilibrium returns are measured. A simple symmetry requirement turns out to be sufficient to rule out this possibility:

Corollary 1. In any equilibrium in which the distribution of types in the markets is symmetrical around zero, if any domestic trade takes place type i's return in the domestic market must equal $\left|\mathrm{z}_{\mathrm{i}}\right| \pi(\mathrm{w})$, where $\left|\mathrm{z}_{\mathrm{i}}\right|$ is his distance from zero. (The proof is in the Appendix.)

In all that follows we concentrate on equilibria where the distribution of types in the markets is symmetrical around zero.

Having characterized equilibrium returns in the last stage of the game--when and if a producer goes back to the domestic market--we can now evaluate under what conditions a producer can be expected to do better internationally. We begin by finding the set of acceptable foreign partners for each home producer and vice-versa. We label the former set $S(i)$ and the latter set $S^{*}\left(i^{*}\right)$. Consider a home country producer of type $z_{i} \geq 0$ (the opposite case is just a 
mirror image). An international match yields $\left[\left|z_{i}-z_{i}\right| \pi(w)-\left(z_{i} \pi(w)+\left|z_{i}\right| \pi\left(w^{*}\right)\right)\right] / 2+z_{i} \pi(w)$, where we have used the fact that internationally matched producers will employ labor in the country where it is cheaper (it is not difficult to see that this can never be the foreign country). The term in square brackets equals the gains from trade, hence the international match is acceptable when:

$$
\left|z_{i}-z_{i^{*}}\right| \geq z_{i}+\left|z_{i}\right| \psi\left(w^{*} / w\right),
$$

where $\psi\left(w^{*} / w\right) \equiv \pi\left(w^{*}\right) / \pi(w) \leq 1 .^{s}$

From (6) we see that only when $w<w^{*}$ (implying $\psi<1$ ) are some "bad matches" $\left(z_{i^{*}}>0\right.$ ) acceptable, and that all "good matches" $\left(z_{i^{*}}<0\right)$ are acceptable for $w \leq w^{*}$ and are strictly preferred when $w<w^{*}$. Foreign producers benefit from access to cheaper labor, but the difference in wages also allows home country producers to benefit from trade by using their superior bargaining power. Using (6), we can show that $S(i)$ is given by:

$$
z_{i *} \in \begin{cases}{[-1,0] \cup\left[[2 /(1-\psi)] z_{i}, 1\right]} & \text { if } z_{i} \in[0,(1-\psi) / 2] \\ {[-1,0]} & \text { if } z_{i} \in[(1-\psi) / 2,1]\end{cases}
$$

Define $p(i)$ as the probability that home producer $z_{i} \geq 0$ encounters an acceptable partner abroad. Recalling that all producers attempt the international market and that the distribution of types is uniform, we have:

$$
p(i)=\operatorname{prob}(i * \in S(i))= \begin{cases}1 / 2+(1 / 2)\left(1-[2 /(1-\psi)] z_{i}\right) & \text { if } z_{i} \in[0,(1-\psi) / 2] \\ 1 / 2 & \text { if } z_{i} \in[(1-\psi) / 2,1]\end{cases}
$$

${ }^{5}$ Note that we can write $\psi$ as a function of only the ratio of wages because $\pi$ is a constant elasticity function. 
The probability of a successful match equals 1 for $z_{i}=0$, and, if $\psi$ is smaller than 1 , declines as $\left|z_{i}\right|$ rises, becoming constant at $1 / 2$ for all $\left|z_{i}\right|$ 's higher than $(1-\psi) / 2$ : only when an individual's domestic alternative yields a low return $\left(\left|z_{i}\right|\right.$ is low) is the bargaining power generated by access to cheap labor sufficient to increase the range of acceptable foreign partners.

For a foreign country producer of type $z_{i^{*}} \geq 0$, an international match yields $\left[\left|z_{i^{*}}-z_{i}\right| \pi(w)-\left(z_{i^{*}} \pi\left(w^{*}\right)+\left|z_{j}\right| \pi(w)\right)\right] / 2+z_{i^{*}} \pi\left(\mathrm{w}^{*}\right)$ and is acceptable when:

$$
\left|z_{i^{*}}-z_{j}\right| \geq z_{j^{*}} \Psi\left(w^{*} / w\right)+\left|z_{i}\right|
$$

Using $\left(6^{*}\right)$, we can show that $S^{*}\left(i^{*}\right)$ is given by:

$$
z_{i} \in\left[-1,[(1-\psi) / 2] z_{i^{*}}\right] \forall z_{j^{*}} \geq 0
$$

It follows that $p^{*}\left(i^{*}\right)$, the probability that foreign producer $z_{i^{*}} \geq 0$ is matched with an acceptable international partner, is:

$$
p^{*}\left(i^{*}\right)=\operatorname{prob}\left(i \in S^{*}\left(i^{*}\right)\right)=(1 / 2)\left(1+[(1-\psi) / 2] z_{i^{*}}\right) \forall z_{i^{*}} \geq 0
$$

Contrary to what happens in the home country, if $\psi$ is smaller than 1 , the probability of a successful international match is monotonically increasing in $\left|z_{i^{*}}\right|$ : the gain from using cheap labor is proportional to $\left|z_{i}\right|$, and thus the incentive to accept a given foreign partner is higher for higher types.

It is informative to compute $P$, the expected share of international matches that are acceptable. Using (8) or $\left(8^{*}\right)$, we have:

$$
P=\int_{0}^{1} p(i) d i=\int_{0}^{1} p *(i *) d i *=(5-\psi) / 8
$$

Note that $P$ equals $1 / 2$ when $\psi=1$ : when wages are equal across the two countries only good matches are acceptable, and the probability of finding a partner on the opposite side of zero equals $1 / 2$ for any home or foreign producer. As $\psi$ falls, an increasing proportion of bad matches 
becomes acceptable, and $P$ increases.

A successful international match generates labor demand equal to $\left|z_{i}-z_{i}\right|\left(-\pi^{\prime}(w)\right)$. If home labor is cheaper, i.e., $\psi$ is smaller than 1, all the international demand will fall on home labor. The presence of $z_{i^{*}}$ in this labor demand expression indicates that "transfer of labor demand" from foreign to home is taking place. Using (7), we can then derive expected total home labor demand as the sum of labor demand from domestic and international matches:

$$
\begin{aligned}
L^{d} & =2 \int_{0}^{(1-\psi) / 2} \frac{-\pi^{\prime}(w)}{2}\left[\int_{-1}^{0}\left(z_{i}-z_{i *}\right) d z_{i *}+\int_{0}^{[2 /(1-\psi)] z_{i}} z_{i} d z_{i *}+\int_{[2 /(1-\psi)] z_{i}}^{1}\left(z_{i *}-z_{i}\right) d z_{i *}\right] d z_{i} \\
& +2 \int_{(1-\psi) / 2}^{1} \frac{-\pi^{\prime}(w)}{2}\left[\int_{-1}^{0}\left(z_{i}-z_{i *}\right) d z_{i *}+\int_{0}^{1} z_{i} d z_{i *}\right] d z_{i}=\left[\left(19-\psi^{2}\right) / 12\right]\left(-\pi^{\prime}(w)\right) .
\end{aligned}
$$

As expected, home labor demand is decreasing in $\psi$ : as $\psi$ increases, the share of international matches that is successful falls, and thus the amount of foreign labor demand that is transferred to the home country decreases. By the same reasoning, we expect foreign labor demand to be increasing in $\psi$ :

$$
L *^{d}=2 \int_{0}^{1} \frac{-\pi^{\prime}(w *)}{2}\left[\int_{[(1-\psi) / 2] z_{i *}}^{1} z_{i *} d z_{i}\right] d z_{i *}=[(2+\psi) / 6]\left(-\pi^{\prime}(w *)\right) .
$$

Using (10) and $\left(10^{*}\right)$ we obtain the two countries' labor market-clearing conditions when home labor is cheaper than foreign labor:

$$
\begin{aligned}
& {\left[\left(19-\psi^{2}\right) / 12\right]\left(-\pi^{\prime}(w)\right)=L} \\
& {[(2+\psi) / 6]\left(-\pi^{\prime}\left(w^{*}\right)\right)=L^{*} .}
\end{aligned}
$$


Our model admits of two types of equilibria, integrated and non-integrated, where we define an integrated equilibrium (IE) as an equilibrium in which $w=w^{*}$ and a non-integrated equilibrium (NIE) as an equilibrium in which $w \neq w^{*}$ (hence $w<w^{*}$ ). We will show that there exists an upper bound $\overline{L / L^{*}}$ on the ratio of factor endowments for which an IE can obtain. But first we establish:

Remark 1. An integrated equilibrium with active domestic markets, if one exists, is equivalent to the equilibrium that would obtain in the integrated world economy. Proof: Let $\underline{w}$ be the wage that clears the world labor market in a given IE. If domestic markets are active, no producer can earn a lower profit than $\left|z_{i}\right| \pi(w)$, the domestic fall-back option, but since $\psi=1$, neither can any producer earn a greater profit. World labor demand must then equal $2\left(-\pi^{\prime}(\underline{w})\right)$. It follows that in any IE $\underline{w}=W$, the equilibrium wage in the IWE, and each producer earns $\left|z_{i}\right| \pi(W){ }^{6}$

For an integrated equilibrium to exist, both national labor markets must clear at $W$. With $L>L^{*}$, this can only be accomplished by shifting enough labor demand from the foreign to the home country through successful international matching. The largest disparity in labor demands occurs when all international matches not strictly dominated by the fall-back domestic option are concluded, and all international labor demand falls on home labor. These conditions are naturally satisfied when the price of home labor is lower, and $\psi$ is smaller than 1 , and we have imposed them above. Thus the upper bound on the ratio of labor supplies compatible with an IE, $\overline{L / L *}$, can be immediately obtained by substituting $w=w^{*}=W$ and $\psi=1$ in (11) and (11*) and dividing, yielding $\overline{L / L *}=3$. We can now state:

Proposition 3. If both domestic and international markets are active, the equilibrium reproduces the integrated world economy if and only if $\mathrm{L} / \mathrm{L}^{*} \leq \overline{\mathrm{L} / \mathrm{L} *}$, where $\overline{\mathrm{L} / \mathrm{L} *}=3$. Proof: By the previous argument, if $L / L^{*}>3$, it is impossible to generate sufficient demand for home labor to equalize wages. Thus the integrated equilibrium requires $L / L^{*} \leq 3$. We prove that

\footnotetext{
${ }^{6} \mathrm{We}$ need to specify that domestic markets are active to rule out the (uninteresting but possible) case where no producer expects any other conational to return home, and thus the fall-back option of domestic matching becomes irrelevant, and all international partnerships are accepted.
} 
an integrated equilibrium (equivalent to reproducing the integrated world economy) necessarily obtains if $L / L^{*} \leq 3$ by contradiction. Suppose that an IE does not obtain. It follows that $\psi<1$. If both domestic and international markets are active, expected total labor demands in the home and in the foreign country are given by $(10)$ and $\left(10^{*}\right)$, respectively. These labor demands respectively exceed and fall below the levels for which $w=W$ and $w^{*}=W$, establishing the contradiction. ${ }^{7}$

It builds intuition to give an alternative derivation for the value of $\overline{\mathrm{L} / \mathrm{L} *}$. In an IE the producers of each country contribute $-\pi^{\prime}(W)$ to world labor demand. The probability that any producer makes a good match in the international market equals one-half. With equal wages, only good matches are acceptable and it follows that at most half of $-\pi^{\prime}(W)$ can be transferred from the labor-scarce to the labor-abundant country, yielding labor demand equal to $(3 / 2)\left(-\pi^{\prime}(W)\right)$ at home and $(1 / 2)\left(-\pi^{\prime}(W)\right)$ abroad, or a ratio of labor demands equal to $3 .^{8}$

Proposition 3 implies that only a non-integrated equilibrium is possible for $L / L^{*}>\overline{L / L *}$. We can show that this equilibrium exists and is unique given $L, L^{*}$, i.e., that for every $L, L^{*}$ such that $L / L^{*}>\overrightarrow{L / L *}$ the home and foreign labor market-clearing conditions have a unique solution $\{\hat{w}, \hat{\psi}\} . \hat{w} *$ is then given by $\pi^{-1}[\hat{\psi} \pi(\hat{w})]$.

Proposition 4. If both domestic and international markets are active, a unique non-integrated equilibrium exists for every $\mathrm{L}, \mathrm{L}^{*}$ such that $\mathrm{L} / \mathrm{L}^{*}>\overline{\mathrm{L} / \mathrm{L} *}$. Proof: Substituting $\pi^{-1}[\psi \pi(w)]$ for $w^{*}$, we can plot (11) and $\left(11^{*}\right)$ in $w, \psi$ space. In Figure 1 these curves are labeled $L L$ and $L^{*} L^{*}$, respectively. It is easily shown that the former curve is negatively sloped and the latter curve is

\footnotetext{
${ }^{7}$ Again, the condition that both domestic and international markets are active is required to rule out less interesting outcomes. If no producer is expected to enter the international market, then there is an equilibrium with no international matching--each country functions in autarky and faces a different equilibrium wage for any $L \neq L^{*}$. If, on the other hand, all domestic producers are expected to accept any international match, then the domestic fall-back option is irrelevant, and equilibrium returns are lower than in the integrated world economy.

${ }^{8}$ Note that this result is independent of the rule we have chosen for the distribution of trade surplus in the international market (the Nash bargaining rule). What matters is that only those matches yielding at least as much as the sum of the two producers' domestic returns are concluded; but labor demand is independent of the individual shares of total profits.
} 
positively sloped, establishing that the solution to (11) and $\left(11^{*}\right)$, if it exists, is unique. We demonstrate existence for $L / L^{*} \in[3, \infty)$ as follows. First, note that since $\pi$ is a constant elasticity function, so is $\pi^{\prime}$. Since $-\pi^{\prime}(w)$ is a decreasing constant elasticity function and $\psi \in[0,1]$, a $w$ exists that solves (11) for any positive $L$. Second, the ratio $\pi^{\prime}\left(w^{*}\right) / \pi^{\prime}(w)$ is a function of $w^{*} / w$ only and can therefore be written as $g(\psi)$, where $g(0)=0$ and $g(1)=1$. Substituting $\pi^{\prime}\left(w^{*}\right)=$ $g(\psi) \pi^{\prime}(w)$ into $\left(11^{*}\right)$ and combining $\left(11^{*}\right)$ with $(11)$ yields $\left(19-\psi^{2}\right) /[2(2+\psi) g(\psi)]=L / L^{*}$, which admits a solution $\psi \in[0,1]$ for $L / L^{*} \in[3, \infty)$. Note that $\psi$ is a function of $L / L^{*}$ only, so that the ratio of home to foreign wages is not affected by the absolute size of the world labor endowment.

In a NIE, country wage levels display "excess sensitivity" to changes in their own endowments, while the wages of their trading partners are "partially insulated" from these changes. This is proved in Proposition 5.

Proposition 5. In a non-integrated equilibrium, an increase (decrease) in a country's labor endowment decreases (increases) its own wage and that of its trading partner, but decreases (increases) its own wage relatively more. Proof: Consider an increase in the labor endowment of the home country. This shifts the $L L$ curve down in Figure 1, causing $\hat{w}$ and $\hat{\psi}$ to decrease, implying an increase in $\hat{w} * / \hat{w}$. By $\left(11^{*}\right)$, the decrease in $\hat{\psi}$ implies a decrease in $\hat{w} *$. The remainder of the proposition can be proved in the same way.

Consider an increase in the home labor endowment. Unless more labor demand is transferred to the home country, its wage must fall more than the foreign wage. But more labor demand can shift towards home labor only if more international matches are successful, and more international matches will be successful only if $\hat{w} * / \hat{w}$ increases. This is the intuition behind Proposition 5 .

In Proposition 3 and its proof we saw that the operation of the price mechanism brings about full efficiency or maximum world income when $L / L^{*} \leq \overline{L / L *}$. When a NIE obtains, we can make the weaker claim that world income increases relative to autarky:

Proposition 6. World income is higher in a NIE than with no trade. Proof: The proof is made easier by considering separately each country. Taking the home country, label the autarky wage $w^{A}$. It is easily shown that aggregate autarky profits equal $\pi\left(w^{A}\right)$, so that $-\pi^{\prime}\left(w^{A}\right)=L$. It follows from (11) that $w^{A}<\hat{w}$. The difference in home income between a given NIE and autarky can be decomposed into $\left[\left(\hat{w}-w^{A}\right)\left(-\pi^{\prime}\left(w^{A}\right)\right)+\left(\pi(\hat{w})-\pi\left(w^{A}\right)\right)\right]+[\hat{\Pi}-\pi(\hat{w})]$, where $\hat{\Pi}$ denotes aggregate profits in the NIE. The second term in brackets is non-negative because traders cannot do worse 
than the domestic fall-back option (it is zero in an integrated equilibrium). The first term in brackets is positive because $\pi$ is a convex function of $w$. An analogous argument shows that foreign income is also higher in the NIE than in autarky, hence world income is higher."

World profits and world wages are also higher with trade than in autarky, because both are a fixed proportion of world income with a constant elasticity profit function.

\section{B. Discussion}

Informational versus traditional barriers to trade. The standard model most closely related to ours is the one-good, two-factor model of trade, analysis of which dates back at least as far as Becker (1957) and MacDougall (1960). Internationally mobile capital in this model plays the same role as producers in our model. The source of gains from trade in the two models is identical. In the standard model a trade barrier typically takes the form of an ad valorem tax on profits earned abroad. Such a tax (or a "taste for discrimination" as in Becker (1957)) drives a constant proportional wedge between home and foreign returns to capital, leading to a constant proportional wedge between home and foreign wage rates. It follows that full efficiency can never be achieved with this trade barrier. In contrast, although an informational barrier, like a traditional trade barrier, is uniform across producers ex ante, ex post some producers effectively evade it if they are "lucky" in their international matching. If there are enough of these good matches relative to the difference between the countries' endowments, wages in the two countries will be equalized and full efficiency will be achieved.

As long as the traditional trade barrier is not prohibitive (trade is positive), the ratio of the home to the foreign wage is insensitive to the ratio of the home to the foreign labor endowment: the relative labor demand curve is horizontal at the relative wage determined by the wedge between home and foreign returns to capital. With an informational barrier, this curve is 
horizontal at one as long as the ratio of labor endowments is not too large relative to the capacity of good matches to transfer labor demand, and becomes downward-sloping when the ratio of labor endowments exceeds this threshold. Moreover, country wage levels become more sensitive to changes in own than foreign endowments, whereas they are equally sensitive with the traditional trade barrier. ${ }^{9}$

Note that in the standard model without trade barriers wages are equalized across countries no matter how far apart are the countries' endowments. The contrast with our model brings up the next topic of discussion.

Margins and volumes. Are choices made at the margin sufficient to equalize prices across different national markets, or is a certain volume of trade across the markets necessary to drive prices to equality? In a perfectly competitive world with no barriers to trade of any kind, this question is not well posed: if prices were not to equalize, the volume of trade required to equalize them would automatically occur. In the real world, this question has been extensively discussed in connection with the analysis of how competition from labor in low-wage countries affects wages of comparably skilled labor in high-wage countries. Freeman (1995, pp. 21-22) elegantly summarizes the debate:

If the West can import children's toys produced by low-paid Chinese workers at bargain basement prices, surely low-skilled westerners, who produce those toys at wages 10 times those of the Chinese, will face a difficult time in the job market. It isn't even necessary that the West import the toys. The threat to import them or to move plants to less-developed countries to produce the toys may suffice to

\footnotetext{
${ }^{9}$ In the standard model, a trade barrier that acts like a specific instead of an ad valorem tax leads to the result that any increase (decrease) in the world labor-capital endowment ratio reduces (increases) the proportionate difference between the two countries' wage rates. A trade barrier that acts like a quota permits achievement of full efficiency when the quota is not binding, but when it is binding changes in countries' endowments can only affect their own wages.
} 
force low-skilled westerners to take a cut in pay to maintain employment. In this situation, the open economy can cause lower pay for low-skilled workers even without trade: to save my job, I accept Chinese-level pay, and that prevents imports. The invisible hand would have done its job, with proper invisibility. ...These predictions [of factor-price equalization] run counter to a wide body of evidence that domestic developments do affect wages: for instance, that the baby boom affected the pay of young workers; that the relative number of college graduates altered the premium paid for education .... ${ }^{10}$

Having recognized the theoretical point that competition from labor in low-wage countries could be felt on wages of comparably skilled labor in high-wage countries even in the absence of any actual trade, the empirical method for quantifying such competition that is preferred by Freeman (1995, p. 23) and many others (see, e.g., Sachs and Shatz 1994) remains factor content analysis:

if the United States imported 10 additional children's toys, which could be produced by five American workers, the effective supply of unskilled workers would increase by five .... This five-worker shift in the supply-demand balance would put pressure on unskilled wages to fall, causing those wages to fall in accord with the relevant elasticity.

Here the impact of low wage competition depends entirely on the volume of net trade and not at all on comparison of prices at the margin.

Our model suggests a way to resolve the tension between these two views. In the integrated equilibrium, the volume of international matches that are acceptable without wage differentials is sufficiently large for margins to operate perfectly: any incipient rise in the foreign wage relative to the home wage can be eliminated by a shift in labor demanded by these internationally matched producers from the foreign to the home country. In the non-integrated

\footnotetext{
${ }^{10}$ We might take the liberty of clarifying Freeman's statement to state that the baby boom affected the pay of young workers more in the United States than in China and the relative number of college graduates in the United States altered the premium paid for education more in the United States than in China.
} 
equilibrium, on the other hand, the volume of these international matches is insufficient for margins to operate perfectly: elimination of an incipient increase in the foreign wage requires that foreign producers shift from matching in a complete information environment domestically to an incomplete information environment abroad. When margins operate imperfectly, relative wages become a downward-sloping function of relative labor supplies in the two countries. In short, the efficient operation of margins is dependent on adequate volume of good matches, where the volume of these matches that is adequate is determined by the ratio of the factor endowments of the two countries.

Integrated and non-integrated equilibrium for a small country. Most countries are "small" relative to the rest of the world. Surely changes in the factor endowments of a small country cannot change factor prices in the rest of the world, so we might conclude that they cannot affect domestic factor prices either. This conclusion is true in the standard model (provided trade is positive) but false in our model. Let us suppose that for every foreign producer there are $N$ corresponding home producers (we have fixed $N$ at one until now). Conjecture that a nonintegrated equilibrium obtains for the world economy. Since all producers attempt to match in the international market and, because of incomplete information, rationing is random with respect to location on the line, any home producer matches with a foreign one with probability $1 / N$. It follows that as $N$ grows large home labor demand is reduced to autarky labor demand, which is now given by $N\left[-\pi^{\prime}(w)\right]$. If we multiply $L$ by $N$ in order to keep the home country ratio of labor to producers constant, the labor market clearing condition for the large home country becomes $N\left[-\pi^{\prime}(w)\right]=N L$ or $\left[-\pi^{\prime}(w)\right]=L$. Given random rationing of home producers, the expected total demand for foreign labor is still given by $\left(11^{*}\right)$. If this demand exceeds supply at the wage 
determined by the large home country, a NIE obtains and the small foreign country can affect its own wage. Substituting $\left[-\pi^{\prime}(w)\right]=L$ for $-\pi^{\prime}\left(w^{*}\right)$ in $\left(11^{*}\right)$ and setting $\psi=1$, we see that demand for foreign labor cannot fall below $L / 2$. Hence a NIE obtains when $L / 2>L^{*}$ or $L / L^{*}>2$, and our conjecture is verified for factor endowments in that range. ${ }^{11}$

\section{Group Ties}

\section{A. Matching}

We now introduce group ties into our model. Suppose that a subset of producers of mass $m$ in each country are members of the same group, within which information is complete.

Belonging to the group provides no advantage in domestic trade, where all producers benefit from complete information, but enriches a producer's options when matching abroad. A group member trading abroad has two possibilities: he can either find a match through the group, in which case he will choose and be chosen as a partner with complete knowledge of all available types; or he can opt for the anonymous market where incomplete information prevails. The decision has to be made ex ante, before the anonymous market has been sampled--in other words, both group members and nonmembers are allowed to sample the international market only once. To avoid distorting our analysis through additional effects, we assume that group members are distributed

\footnotetext{
${ }^{11}$ Why is the upper bound on $L / L^{*}$ for which an IE can obtain smaller than when the masses of producers in the two countries were equal? The answer is that the wage rate determined by $\left(-\pi^{\prime}(w)\right)=L$ is smaller than the wage rate determined by $(11)$ evaluated at $\psi=1$. With a smaller wage rate the demand for foreign labor evaluated at $\psi=1$ is larger and thus exceeds a larger value of $L^{*}$. The reader can easily show that when the foreign country is the large country the upper bound on $L / L^{*}$ for which an IE can obtain equals $3 / 2$, again smaller than 3 . The wage rate determined by $\left(-\pi^{\prime}\left(w^{*}\right)\right)=L$ is larger than the wage rate determined by $\left(11^{*}\right)$ evaluated at $\psi$ $=1$, hence the maximum home labor demand that home labor supply must exceed for a NIE to obtain is smaller.
} 
uniformly over the whole support: there is nothing different about members, but for their privileged access to information in international ventures. A fortunate by-product of this distributional assumption is that we do not need to take a stance on the difficult question of whether or not group members can function as middlemen, providing introductions between foreign members and domestic producers who do not belong to the group. Because all types are represented in the group, access to group members only, or, through them, to their co-nationals are equivalent. ${ }^{12}$

The timing of moves now is the following. First, all producers go to the international market, and group members decide whether to match anonymously or through the group. Then, in anonymous matches types are revealed, and all successful partnerships are concluded. Finally, producers in unacceptable international matches return to their countries and match domestically. As before, the labor markets clear when all labor demands, from international and domestic matches, are received.

A producer with access to group ties must decide whether or not to exploit them. His evaluation, and our analysis, must begin by characterizing individual returns when matching internationally through the group: the match occurs with complete information about types, and producers from each country are constrained to matching with a partner from the other country. Proposition 7 provides the answer we need:

Proposition 7. In any equilibrium in which the distribution of types in the markets is symmetrical around zero, a home country producer matching internationally through the group will receive $\left|z_{i}\right| \pi(\mathrm{w})+\mathrm{k}$, and a foreign country producer $\left|z_{i}\right| \pi(\mathrm{w})-\mathrm{k} . \mathrm{k}$ is non-negative and such that no group member who strictly prefers matching through the group is unable to find a

\footnotetext{
${ }^{12}$ This is true as long as nonmembers cannot take the initiative and effectively nullify the informational barriers by exploiting domestic links to group members.
} 
partner. (The proof is in the Appendix.)

Suppose, for example, that the share of group members willing to use the ties were higher in the foreign country. Then some of them would be unable to find partners and would have an incentive to secure a match by offering a larger $k$ to home producers matching through the group. The increase in $k$ must induce more home group members to use the ties, and discourage some foreign ones from doing so. In equilibrium $k$ must be such that, as stated in the proposition, no group member who wants to use the ties is unable to find a partner. Note that $k$ cannot be negative, since all group members from the home country would then avoid the ties, being guaranteed higher returns in their domestic market.

\section{B. Equilibrium}

Intuitively, the existence of group ties providing the option of complete information in international matches plays two main roles. First, it diminishes the overall severity of the informational barriers. Thus we expect that the volume of good matches should rise, and with it the pressure towards factor price equalization: larger disparities in labor supplies should now become consistent with equal wages in the two countries. Second, access to information is limited to a specific group: the connected producers within the whole set of producers in each country. In general, and in line with the results in Casella and Rauch (1997), we expect the actions of this group to have distributive effects, as the benefits from their existence fall unequally on market participants. ${ }^{13}$

${ }^{13}$ Of course, the effect of the ties on prices has distributive effects in itself: as the world approaches an IE, in each country the scarce factor should lose and the relatively abundant factor gain. Here we want to distinguish the possibility of distributive effects between group members and nonmembers, aggregating across countries. 
We consider integrated equilibria first. If wages are equal in both countries, it follows from Proposition 7 that $k=0$, since otherwise all foreign group members would choose to enter the anonymous international market. In an IE, therefore, the profit earned by both group members and nonmembers is $\left|z_{i}\right| \pi(W)$. An integrated equilibrium is still equivalent to the integrated world economy when group ties are present.

The largest disparity in labor supplies consistent with an IE is obtained, as before, by constructing the largest possible disparity in labor demands, consistent with equilibrium. Suppose that all group members use the ties, all acceptable international matches, in the group and in the market, are concluded, and all labor demand originating in international partnerships falls on home country labor. Then we obtain: ${ }^{14}$

$$
\begin{aligned}
& \bar{L}=[(6+m) / 4]\left(-\pi^{\prime}(W)\right) \\
& \overline{L *}=[(2-m) / 4]\left(-\pi^{\prime}(W)\right),
\end{aligned}
$$

or:

Proposition 8. If both domestic and international markets are active, when group ties are present there exists an equilibrium that reproduces the integrated world economy if $\mathrm{L} / \mathrm{L}^{*} \leq$ $\overline{\mathrm{L} / \mathrm{L} *}$, where $\overline{\mathrm{L} / \mathrm{L} *}=(6+\mathrm{m}) /(2-\mathrm{m})$.

Notice that, as expected, the ratio is larger the larger is $m$, the share of producers with access to

${ }^{14}$ In lieu of detailed derivations of $(12)$ and $\left(12^{*}\right)$ we supply the following intuition. As before, in an IE the producers of each country contribute $-\pi^{\prime}(W)$ to world labor demand. We can decompose this into the portion supplied by nonmembers, $[(2-m) / 2]\left(-\pi^{\prime}(W)\right)$, and the portion supplied by members, $(m / 2)\left(-\pi^{\prime}(W)\right)$. The probability that any nonmember producer makes a good match in the international market equals one-half, so at most half of $[(2-m) / 2]\left(-\pi^{\prime}(W)\right)$ can be transferred from the labor-scarce to the labor-abundant country, leaving foreign labor demand equal to $[(2-m) / 4]\left(-\pi^{\prime}(W)\right)$. In contrast, all of $(m / 2)\left(-\pi^{\prime}(W)\right)$ can be transferred from the foreign to the home country, yielding home labor demand equal to $[(2-m) / 2+(2-m) / 4+m]\left(-\pi^{\prime}(W)\right)=$ $[(6+m) / 4]\left(-\pi^{\prime}(W)\right)$. 
the ties; it is higher than 3 for any positive $m$, and approaches infinity as $m$ approaches 2 . By increasing the volume of good matches, ties expand the range of factor-endowment differences within which margins can operate perfectly and trade achieve the efficient allocation of resources. $^{15}$

When wages are equal in the two countries, access to the ties does not provide any particular advantage because identical returns can be obtained in the domestic markets. Thus, if the introduction of group ties moves the world economy from a NIE to an IE, world profits of group members do not increase any more on average than world profits of nonmembers. If an IE does not obtain, international matching is strictly more profitable in expectation than domestic matching, and we can expect group members to gain more on average than nonmembers given their information advantage in the international market. In a related model, where greater profitability of international matching is given exogenously rather than generated by an international wage differential, Casella and Rauch (1997) show that world profits of nonmembers actually fall after the introduction of group ties. This occurs because group members who make the most desirable trading partners always match through the ties, worsening the composition of the international market.

We can show that analogous results hold in the present model when a NIE obtains after the introduction of group ties. Since the logic is discussed in detail in Casella and Rauch (1997), we simply list the results of interest and give the appropriate intuition, confining all proofs to the

${ }^{15}$ While a NIE must obtain when $L / L^{*}>(6+m) /(2-m)$, both an IE and a NIE can obtain when $L / L^{*}$ is less than but sufficiently close or equal to $(6+m) /(2-m)$. The reason is that, as we see below, some group members choose not to use their ties in a NIE, inhibiting transfer of labor demand across countries sufficiently to allow a wage differential to persist when $L / L *$ is close enough to $(6+m) /(2-m)$. 
Appendix. ${ }^{16}$ The following propositions apply in any symmetrical equilibrium with unequal wages

if both domestic and international markets are active:

Proposition 9. There exists a positive number $\alpha$ such that in both countries all group members in $[-\alpha, \alpha]$ prefer the market (at least weakly), and all group members in $[-1,-\alpha) \cup(\alpha, 1]$ prefer the ties (at least weakly). The intuition is that random matching in the anonymous international market compresses the distribution of expected profits relative to matching within the group, causing group members located near zero (one) to prefer the market (group), given the need to choose between them ex ante.

Proposition 10. Introduction of group ties causes world income, world profits, and world wages to rise. Here the intuition is that the additional labor demand transferred from the labor-scarce to the labor-abundant country by the group more than offsets any reduction in transfer of labor demand resulting from the worsened composition of the anonymous international market.

Proposition 11. There exists an $\overline{\mathrm{m}} \in(0,2)$ above which introduction of group ties must cause world profits of nonmember producers to rise and below which introduction of group ties can cause world profits of nonmember producers to fall. For $m$ sufficiently large the world economy approaches an IE, in which world profits as a whole are maximized and so are world profits of nonmember producers, since they are distributed uniformly over the entire support. For $m$ sufficiently small the market composition effect can dominate this efficiency effect. ${ }^{17}$

The negative impact of the market composition effect on nonmember producers assumes that they cannot discriminate between group members and nonmembers in the anonymous international market. Group membership is typically not readily identifiable ${ }^{18}$ (much to the lament of empirical researchers), even in cases where one might think otherwise. While coethnicity or

${ }^{16}$ The relevant comparison is the "fixed location" case in Casella and Rauch (1997).

${ }^{17}$ It can be shown analytically that the market composition effect is always negative, i.e., holding wages constant, world profits of nonmember producers are lower with than without group ties. In the numerical simulations we ran, the plot of the difference between total nonmember profits with and without ties against $m$ was always a $U$-shape starting from the origin.

${ }^{18}$ A good example is "former employees of IBM." Many of the key decision makers in the hard disk drive industry had worked together at IBM before moving to other firms, and sharing of information among them contributed to the rapid spread of popularity of Singapore as a site for foreign direct investment, according to industry observers (McKendrick 1998). 
business group membership may be transparent to home country nationals, it may often not be for foreigners. A Thai national may recognize that another Thai businessman is of ethnic Chinese origin, but an Indonesian national (not of ethnic Chinese origin) may not be able to. ${ }^{19}$ Encaoua and Jacquemin (1982, p. 26) note that business groups in France "have no legal existence and are not identified in official censuses. Each subsidiary maintains its legal autonomy and keeps separate accounts." 20

We can summarize this section as follows. First, group ties reinforce the ability of prices to allocate resources efficiently across countries. Second, when group ties do not move the world economy to full efficiency, they always benefit group members and those complementary to the group (labor), but may make those in competition with the group worse off.

\section{When Prices and Ties Conflict}

We saw in the previous section that ties and prices work together to improve the allocation of resources. If there is more than one international market, however, ties need not be most dense in the international market where the price differential in their absence is greatest, and

${ }^{19}$ Weidenbaum and Hughes (1996, p. 26) note that "the overseas Chinese have attempted to blend in with their local cultures. Many change their names to avoid persecution. Corazon Aquino's maiden name--Cojuangco--appears to be Spanish but in reality is derived from her immigrant grandfather's name--Ko Hwan Ko. In Thailand, ethnic Chinese were required to take Thai names from a government list."

${ }^{20}$ If however group membership were observable, nonmembers could protect themselves from the negative effects of the ties on the composition of the market by refusing to match with group members when the latter prefer the anonymous market. In this case, an equilibrium exists with complete segregation; all group members are forced to use the ties, and non-members match exclusively among themselves. In this scenario group members as a whole lose relative to the equilibrium without discrimination. 
thus need not reinforce the allocative effect of prices.

Group ties being most dense between countries with smaller wage differentials is not a purely hypothetical situation. Consider the movement offshore of the Korean and Taiwanese apparel industries, which accelerated in the late 1980s and early 1990 s in response to sharply rising domestic wages. Gereffi (1998, p. 25) states, "The preference of Korean firms for investment in Latin America (Guatemala, Honduras, the Dominican Republic, etc.) is stimulated by its proximity to the U.S. market and easy quota access. The pull of Asian nations such as Indonesia, Sri Lanka, and Bangladesh comes mainly from their wage rates, which are among the lowest in the world." In contrast, Taiwanese firms invested most heavily in China, Malaysia, the Philippines, and Thailand as well as Indonesia. Ethnic Chinese ties are important in all of these countries, and in at least two (Malaysia and Thailand) wages are well above South Asian levels. Gereffi concludes (p. 30), "social ties shape sourcing networks."

Since in order to analyze a situation in which prices and ties conflict we need a model in which there is more than one international market, in this section we expand our model to include three countries, ranked from lowest to highest labor-producer ratio. The masses of producers in countries 1 and 2 both equal 2, and the mass of producers in country 3 is at least as great as the sum of the masses of producers in the other two countries. There are now three international markets: between countries 1 and 3,2 and 3, and 1 and 2. We assume that all three markets open simultaneously.

Let us first consider the model without ties. It is easy to show that, given appropriate endowments, an equilibrium exists in which (a) country 1 has the highest and country 3 the lowest wage, (b) all producers in country 1 match with a uniformly distributed subset of producers in 
country 3 , (c) all producers in country 2 also match with a uniformly distributed subset of producers in country 3 , and (d) any remaining (i.e., rationed) country 3 producers return home and match domestically. As before, producers who form unsuccessful international partnerships must also return home and match domestically, and labor markets clear after all labor demands from international and domestic partnerships are received. We will call such an equilibrium the baseline solution.

Starting from this base, we explore the effects of group ties between country 1 and country 2. These ties are modeled as in the previous section, with the subset of producers who are group members being uniformly distributed and of mass $m$ in both countries. Note that when nonmember producers behave as in the baseline solution, the anonymous market between countries 1 and 2 is not active (because all nonmember producers from countries 1 and 2 match with producers from country 3 ), hence the only alternative to use of the ties is matching with country 3 producers.

We need to introduce some additional notation: $w^{1}, w^{2}$, and $w^{3}$ denote the wages in countries 1,2 , and 3 , respectively; $\psi^{1} \equiv \pi\left(w^{1}\right) / \pi\left(w^{3}\right) ;$ and $\psi^{2} \equiv \pi\left(w^{2}\right) / \pi\left(w^{3}\right)$. In the baseline solution, $\psi^{1}<\psi^{2} \leq 1$. Note that use of the group ties necessarily entails use of a resource whose cost is weakly higher (country 2 instead of country 3 labor). We begin by deriving the intuitive result that use of the ties declines as this price incentive not to use them increases.

Proposition 12. Consider any symmetrical equilibrium with group ties between countries 1 and 2 in which nonmember producers behave as in the baseline solution and all domestic markets are active.

i) If $\psi^{2}=1$, all group members use their ties.

ii) If $\psi^{2}<\left(1+3 \psi^{1}\right) / 4$, no group members use their ties. 
iii) If $\left(1+\psi^{1}\right)\left(3+\psi^{1}\right) / 8<\psi^{2}<1$, there exists a unique positive number $\alpha\left(\psi^{1}, \psi^{2}\right)$ such that in country 1 all group members in $[-\alpha, \alpha]$ prefer the market and all group members in $[-1,-\alpha) \cup(\alpha, 1]$ prefer the ties and in country 2 all group members in $(-\beta, \beta)$ prefer the ties and all group members in $[-1,-\beta] \cup[\beta, 1]$ prefer the market, where $\beta=1-\alpha$. Moreover, $\partial \alpha / \partial \psi^{2}<0$ and $\partial \alpha / \partial \psi^{1}>0$. (The proof is in the Appendix.)

We see from Proposition 12 that all group members use their ties when wages in countries 2 and 3 are equal, and no group members use their ties if the wage in country 2 is too large relative to that in country 3 (e.g., $\psi^{2}<1 / 4$ rules out any use of the ties regardless of $\psi^{1}$ ) or when wages in countries 1 and 2 are too close (note that $\psi^{2}<\left(1+3 \psi^{1}\right) / 4$ holds if $\psi^{2}=\psi^{1}$ since $\psi^{1}<1$ ). We also see that $1-\alpha$, the share of group members that uses the ties, declines when the wage in country 2 rises relative to that in country 3 or when the wages in countries 1 and 2 converge (absolutely, or relative to the wage in country 3), given $\left(1+\psi^{1}\right)\left(3+\psi^{1}\right) / 8<\psi^{2}<1$ (a condition only slightly more restrictive than one that guarantees at least some group members will use their ties). ${ }^{21}$

A natural question is whether ties that involve a large group can sustain a wage in country 2 significantly higher than that justified by "market fundamentals." As $m$ increases, an increasing share of labor demand generated by country 1 producers is diverted from country 3 to country 2 , holding $\alpha$ constant. Demand for country 1 labor falls since fewer international matches by

${ }^{21}$ Country 2 is similar to the home country in section $V$ in that it has the lower wage of the two countries linked by ties. Yet in Proposition 12 iii) the group members from country 2 who prefer the market are positively selected, in contrast to Proposition 9 where group members from the home country who prefer the market are negatively selected. The difference results from the fact that country 2 producers who enter the anonymous market must match with country 3 producers who have greater bargaining power, while home country producers who enter the anonymous market match with foreign country producers who have weaker bargaining power. For example, the home country producer located at zero obtains an expected return greater than zero in the anonymous market compared to an expected return equal to zero for the country 2 producer in the same location. 
country 1 producers are unsuccessful. We thus expect an increase in $w^{2}$ relative to $w^{3}$ and some convergence between $w^{1}$ and $w^{2}$. However, the proportion of group members using the ties, $1-\alpha$, will fall as a result. If group members abandon use of their ties too fast, the existence of ties between the intermediate- and high-wage countries will do little to raise wages in the former relative to the low-wage country.

We illustrate the evolution of wage differentials in the world economy as ties between countries 1 and 2 intensify in the following simulation. Since our main interest is in the ability of ties to sustain higher wages than market fundamentals would allow, we choose parameters so that in the absence of ties (i.e., in the baseline solution) wages in countries 2 and 3 are equal, but countries 2 and 3 are just on the border between an IE and a NIE so that any additional demand for country 2 labor must raise $w^{2}$ above $w^{3}$. In order to focus on country 2 , we assume that country 3 is "large" relative to countries 1 and 2 so that its wage is unaffected by labor demand from country 1 and country 2 producers. We then know from section IV.B that $L^{3} / L^{2}=2$ is required to yield both a NIE and $\psi^{2}=1 .{ }^{22}$ Finally, we assume a Cobb-Douglas production function with labor share $=1 / 2$, yielding $\pi(w)=1 / w$.

The results of the simulation are shown in Figure 2. We see that ties with a country whose wages are 50 percent above those of the low-wage country in the absence of ties can raise the wages of country 2 as much as 21 percent, and reduce the ratio of the country 1 to the country 2 wage from 1.5 to below 1.1 . We also see that more than half of the effect of ties on $w^{2}$ when all producers are group members is obtained when only ten percent of producers are group

\footnotetext{
${ }^{22}$ In the simulation of Figure $2, L^{3} / L^{1}=81 / 16$ and $L^{3} / L^{2}=2$, where $L^{3} / L^{1}$ and $L^{3} / L^{2}$ denote the ratios of labor-producer endowment ratios for countries 3 and 1 and countries 3 and 2, respectively.
} 
members, and that virtually all effects of ties on wages are exhausted when the share of group members reaches 40 percent. ${ }^{23}$ Our model thus suggests, for example, that ethnic Chinese ties between Malaysia and Thailand and high-wage countries like Hong Kong, Singapore, and Taiwan can cause wages in the former countries to be significantly higher than in countries lacking those ties, all else equal.

Whether or not country 3 is large relative to countries 1 and 2 , it is easy to see that if wages in countries 2 and 3 are sufficiently close in the baseline solution, ties between countries 1 and 2 must raise world income. First note that autarky world income is the same with and without ties, so we can focus on the way ties change the gains from trade. The source of gains from trade is the transfer of labor demand from a high-wage to a low-wage country. Since matches within the group never fail, ties increase the transfer of labor demand out of country 1 , thereby increasing the gains from trade. However, ties also cause labor demand to be shifted from country 3 to country 2 . As the baseline wage of country 2 approaches that of country 3 the loss of gains from trade from the "trade diversion effect" approaches zero while the increased gains from trade from the "trade creation effect" get larger.

The same argument implies that the increase in world income from group ties declines as the country 2 wage rises relative to the country 3 wage in the baseline solution. This argument cannot establish the possibility of a decrease in world income from group ties, however, because the trade creation effect cannot be made arbitrarily small relative to the trade diversion effect: all group members choose not to use their ties when the wages in countries 2 and 1 get too close, so the effect of ties on world income goes to zero. We have instead established this possibility

$$
{ }^{23}\left(1+\psi^{1}\right)\left(3+\psi^{1}\right) / 8<\psi^{2} \leq 1 \text { always holds in this simulation and in the next. }
$$


through simulation.

In the simulation shown in Figure 3 the mass of producers in country 3 equals 4 and $m$ is held constant at ten percent of the country 1 and country 2 producers. Starting from labor endowments that yield a NIE with $\psi^{2}=1$ in the absence of ties, labor is reallocated among the three countries so as to raise the baseline value of $w^{2} / w^{3}$ above one while maintaining the baseline value of $w^{1} / w^{3}$ constant at 2 . We again assume a Cobb-Douglas production function with labor share $=1 / 2$. We see that gains from trade with ties fall below baseline gains when the baseline country 2 wage exceeds that of country 3 by more than 15 percent. It follows that for these parameters a prohibitive tax on trade between countries 1 and 2 yields higher world income than "free trade." The negative effect of group ties on world income must ultimately be reversed as the baseline value of $w^{2} / w^{3}$ increases since use of the ties must go to zero.

\section{Conclusions}

Informational barriers to trade operate very differently from traditional barriers. Some agents will be lucky in their matches and effectively evade the informational barrier, and if enough of them do so full efficiency can be achieved. If factor endowment ratios are sufficiently different, however, transfer of resource demand by these agents is inadequate to equalize resource prices. Instead, the ratio of prices of the immobile resource across countries becomes a decreasing function of relative country supplies, with each country's price partially insulated from changes in the other country's endowment. An international information-sharing network facilitates the transfer of resource demand and increases the extent to which factor endowment ratios can differ without ruling out achievement of full efficiency. When a price differential persists, however, this 
presence of group ties may hurt agents who are not members of the group. Moreover, price signals and ties may conflict when ties are not most dense between countries with the greatest difference in factor endowment ratios. In this case group ties can actually reduce world income through harmful "trade diversion."

We hope that this paper will further two research programs, both designed to integrate existing strands of literature. First, labor economics suggests that the impact of trade on relative wages across countries operates through changes in relative labor supplies that are a function of trade volume, while international trade theory suggests that this impact operates through price competition at the margin. Our paper suggests that the efficient operation of margins is itself dependent on an adequate volume of trade. Second, while general equilibrium theory sees prices as the dominant means of allocating scarce resouces, social network analysis assigns the same role to the pattern of ties between agents (e.g., Burt 1992). The importance of integrating the two approaches is seen most clearly when prices and ties suggest conflicting actions to agents: ties may cause prices to move out of line with "market fundamentals," and the allocative function of prices that are consistent with market fundamentals may be impaired by the pattern of ties. 


\section{References}

Becker, Gary S. 1957. The Economics of Discrimination (Chicago: University of Chicago).

Becker, Gary. 1973. “A Theory of Marriage: Part 1." Journal of Political Economy 81: 813-46.

Burt, Ronald S. 1992. Structural Holes: The Social Structure of Competition (Cambridge, MA: Harvard).

Casella, Alessandra, and James E. Rauch. 1997. "Anonymous Market and Group Ties in International Trade." National Bureau of Economic Research Working Paper No. 6186 (September).

Encaoua, David, and Alexis Jacquemin. 1982. "Organizational Efficiency and Monopoly Power: The Case of French Industrial Groups." European Economic Review 19: 25-51.

Engel, Charles, and John H. Rogers. 1996. "How Wide Is the Border?" American Economic Review 86 (December): 1112-1125.

Feldstein, Martin S., and Charles Horioka. 1980. "Domestic Saving and International Capital Flows." Economic Journal 90 (June): 314-329.

Freeman, Richard B. 1995. "Are Your Wages Set in Beijing?" Journal of Economic Perspectives 9 (Summer): 15-32.

Gale, David, and Lloyd Shapley. 1962. "College Admissions and the Stability of Marriage." American Mathematical Monthly 69: 9-15.

Gereffi, Gary. 1998. "International Trade and Industrial Upgrading in the Apparel Commodity Chain." Journal of International Economics, forthcoming.

Gordon, Roger H., and A. Lans Bovenberg. 1996. "Why is Capital So Immobile Internationally? Possible Explanations and Implications for Capital Income Taxation." American Economic Review 86 (December): 1057-1075.

Gould, David M. 1994. "Immigrant Links to the Home Country: Empirical Implications for U.S. Bilateral Trade Flows." Review of Economics and Statistics 76 (May): 302-316.

Granovetter, Mark. 1994. "Business Groups." In Neil J. Smelser and Richard Swedberg, eds., The Handbook of Economic Sociology (Princeton, NJ: Princeton). 
Head, Keith, and John Ries. 1998. "Overseas Investment and Firm Exports." University of British Columbia, working paper.

McCallum, John. 1995. "National Borders Matter: Canada-U. S. Regional Trade Patterns." American Economic Review 85 (June): 615-623.

MacDougall, G.D.A. 1960. "The Benefits and Costs of Private Investment from Abroad: A Theoretical Approach." Economic Record, Special Issue, March.

McKendrick, David (Research Director for UCSD Data Storage Project). 1998. Personal communication (February).

Mortensen, Dale T. 1988. "Matching: Finding a Partner for Life or Otherwise." American Journal of Sociology 94: S215-240.

Rauch, James E., and Vitor Trindade. 1998. "Ethnic Chinese Networks in International Trade." University of California, San Diego, working paper.

Sachs, Jeffrey D., and Howard J. Shatz. 1994. "Trade and Jobs in U.S. Manufacturing." Brookings Papers on Economic Activity 1: 1-84.

Sattinger, Michael. 1993. "Assignment Models of the Distribution of Earnings." Journal of Economic Literature 31 (June): 831-880.

Weidenbaum, Murray, and Samuel Hughes. 1996. The Bamboo Network (New York: The Free Press). 


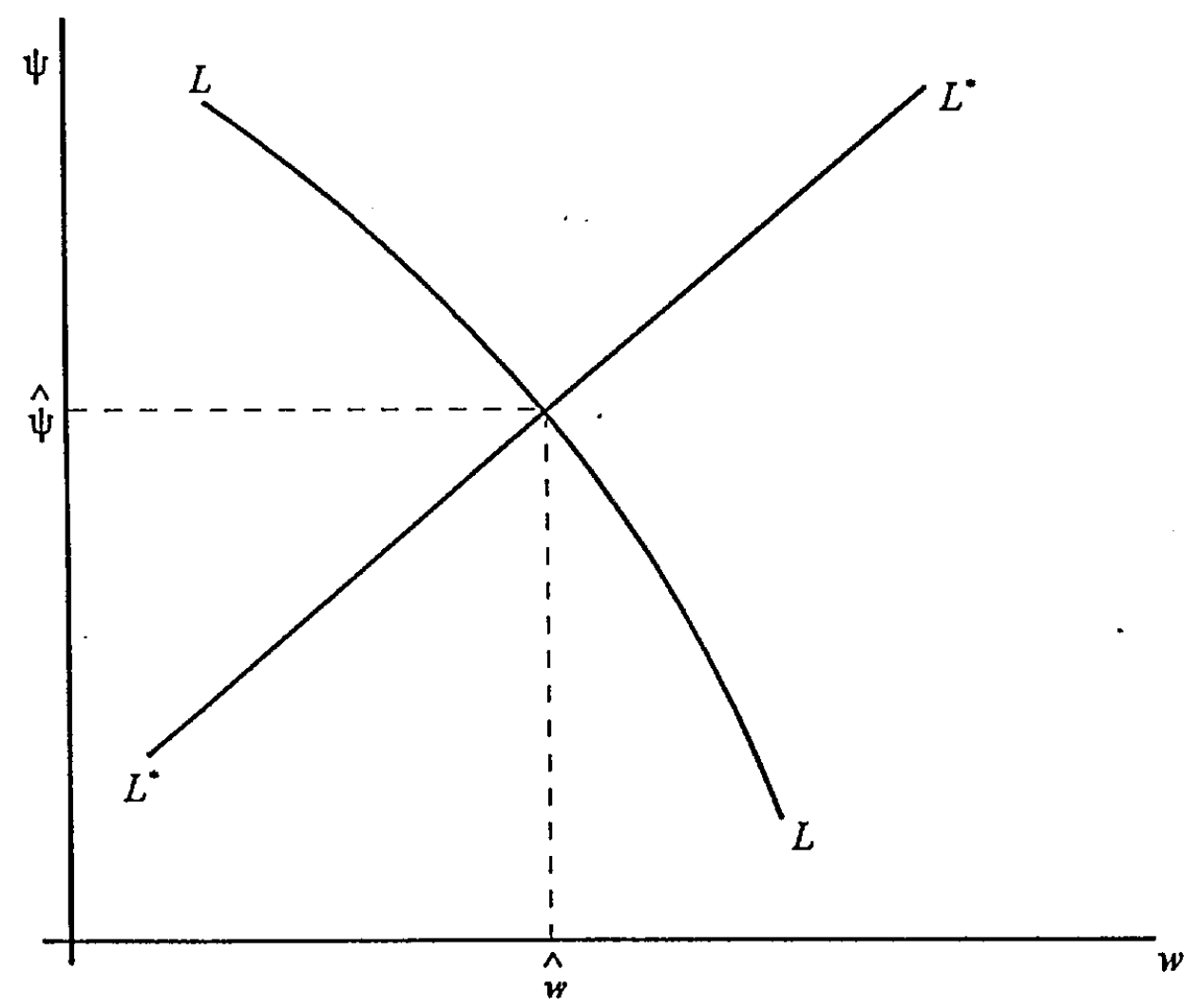

Figure 1: Wage determination in the non-integrated equilibrium 


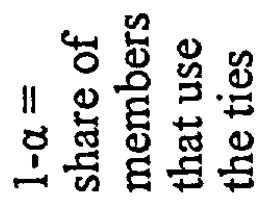

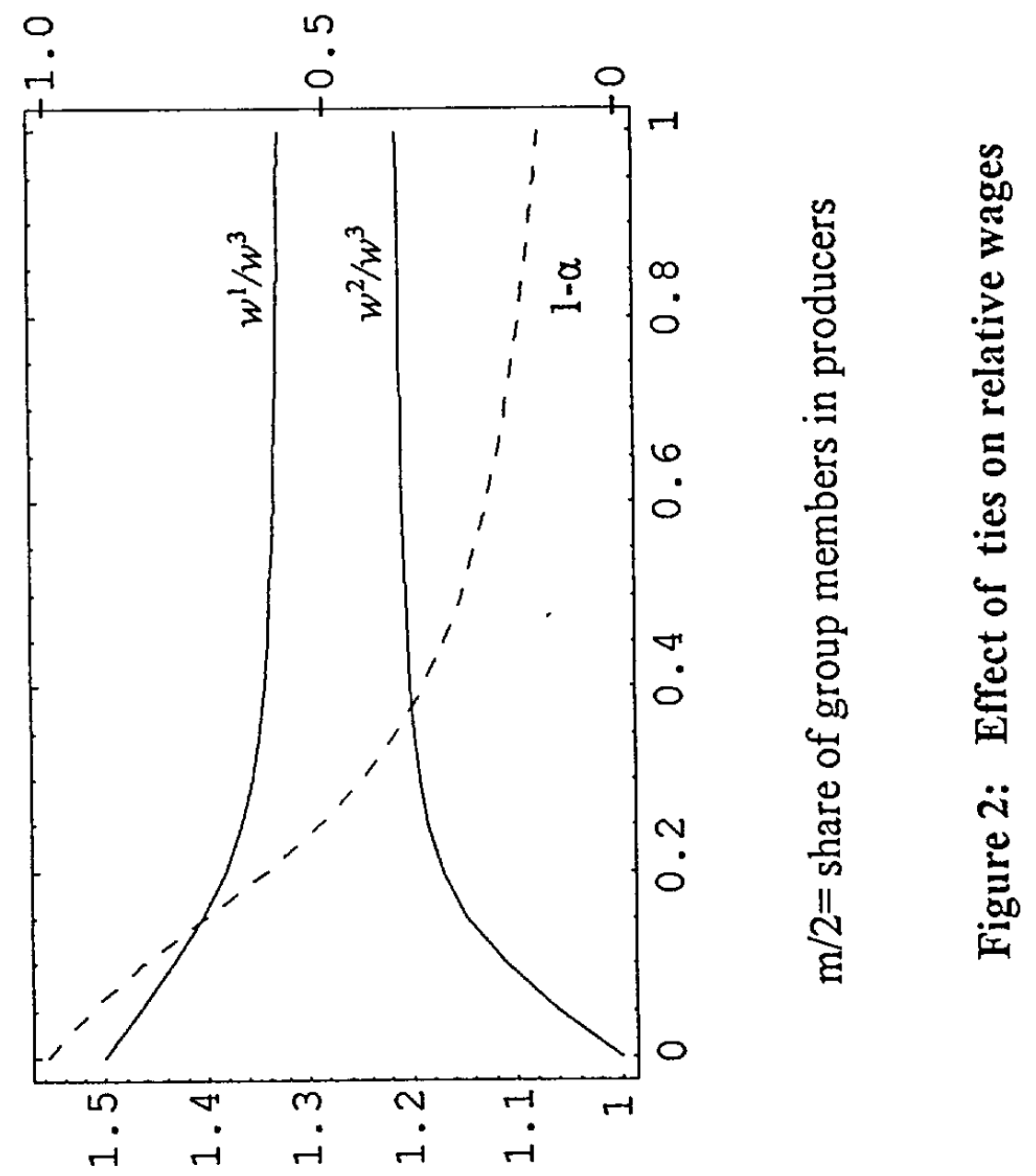

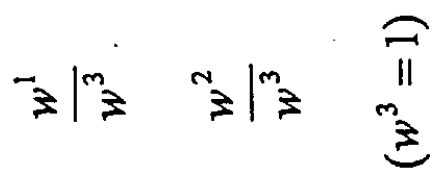




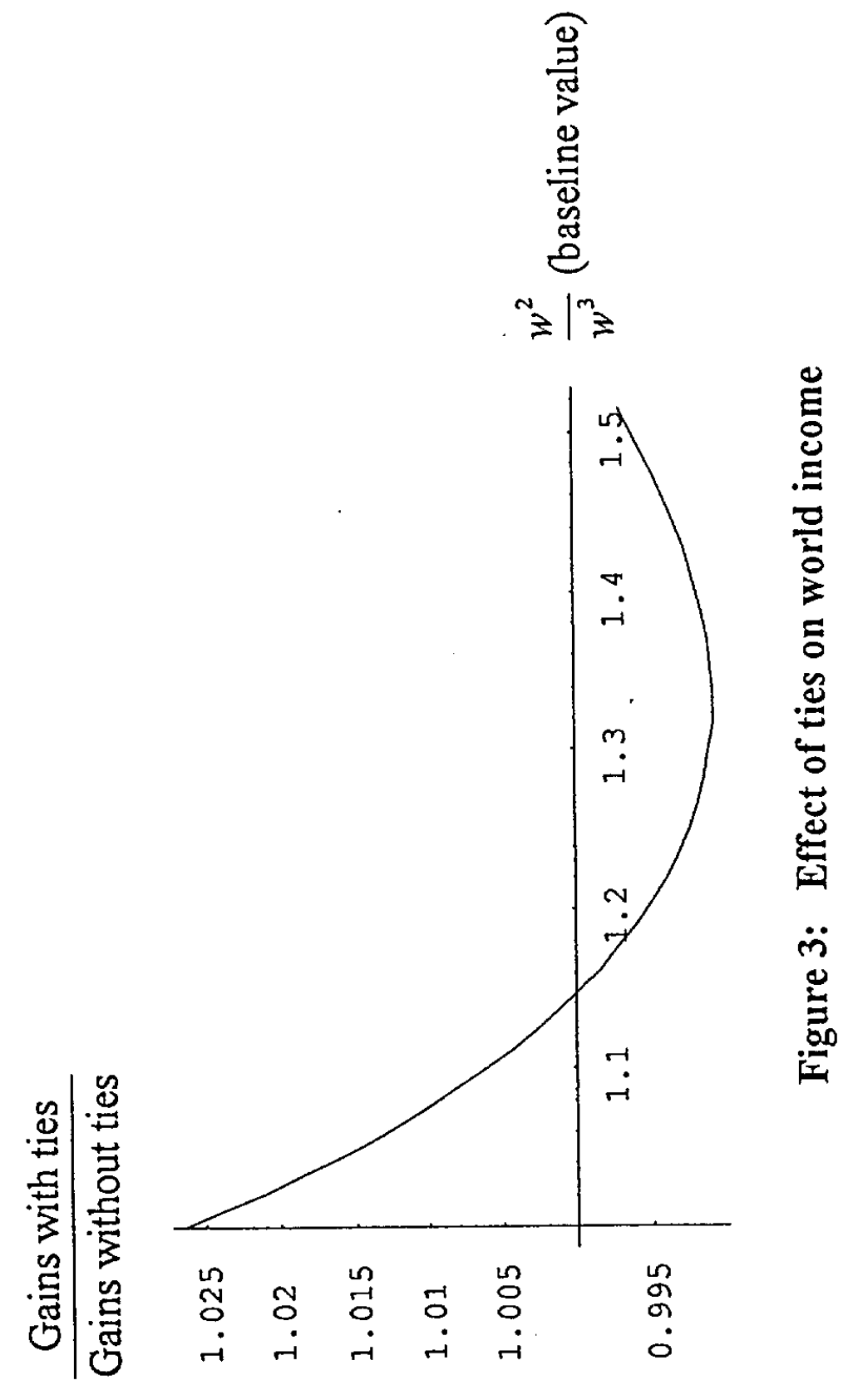


Appendix

Proof of Proposition 1. The proof, in Casella and Rauch (1997), is reproduced here for convenience. We begin by establishing the following Lemma:

Lemma 1. In equilibrium there can be no set of types of positive measure who match with partners located on the same side of the median.

Proof of Lemma 1. Suppose this were the case. Then there must be a set of types of equal measure on the opposite side of the median who match among themselves. But then it is always possible to create new partnerships with each member located on a different side of the median such that both partners are at least as well-off. Suppose that types $j$ and $s$, on the same side of the median, were matched with each other. Then the maximum possible return to either partner is $C$ $z_{j s}$ when he appropriates the entire return from the match. For at least one of the partners, say $j$, it must be that $z_{j s}<\left\|z_{j}\right\|$ (unless $s$ is located at the median and $z_{j s}=\left\|z_{j}\right\|$ ). Similarly, if $i$ and $v$, on the opposite side of the median from $j$ and $s$, match among themselves, either one can obtain at most $C z_{i v}$, and for at least one of the partners, say $i$, it must be that $z_{i v}<\left\|z_{i}\right\|$ (unless $v$ is located at the median and $\left.z_{i v}=\left\|z_{i}\right\|\right)$. By matching among themselves $j$ can earn $C\left\|z_{j}\right\|$ and $i$ can earn $C\left\|z_{i}\right\|$; each type's return is strictly higher than in the original scenario unless his previous partner was located at the median, in which case the return is unchanged.

Thus in what follows we will ignore the possibility of equilibrium matches occurring between partners on the same side of the median.

Suppose first that the distribution of types has a unique median. Consider types $i$ and $j$, on opposite sides of the median. They can always match, produce $C z_{i j}$ and share it as $C\left\|z_{i}\right\|$ to $i$ and $C\left\|z_{j}\right\|$ to $j$. Thus in equilibrium they cannot both earn less. Can at least one of them earn more (for example, can $j$ earn $C\left\|z_{j}\right\|+k$, with $k>0$ )? Only if $j$ matches with $w$ (on the opposite side of the median) who accepts $C\left\|z_{w}\right\|-k\left(C\left\|z_{w}\right\| \geq k\right)$. But this can only occur if all types $v$ on $w$ 's side of the median are receiving $C\left\|z_{v}\right\|-k$. (Suppose that there exists a $v$ who is matched with $s$ and receives $C\left\|z_{v}\right\|-d, d<k$. Then there exists an $\epsilon>0$ such that $w$ can undercut $v$, offer $C\left\|z_{s}\right\|+d+\epsilon$ to $s$ and be better off.)

But all $v$ receiving $C\left\|z_{v}\right\|-k$ cannot occur in equilibrium because any $v$ can then match with a type on the same side of the median, but arbitrarily close to it and make both better off. Thus, if the support of the distribution is continuous around the median, the return to $j$ must equal $C\left\|z_{j}\right\|$ and the return to $i C\left\|z_{i}\right\|$.

Suppose now that there exists a discrete interval of length $2 A$ in the immediate neighborhood of the median over which the mass of types equals zero. Call $\left\langle z_{i}\right\rangle$ type $i$ 's distance from the midpoint of the interval. Each type $i$ on one side of the interval earns individual return $C\left\langle z_{i}\right\rangle-k(k z$ 0 ), and each type $j$ on the opposite side earns $C\left\langle z_{j}\right\rangle+k$. Following the logic detailed above, the 
parameter $k$ must be the same for every type and $k$ must be smaller than $A$ (since underbidding would otherwise be possible), but no profitable deviation exists for all $k \leq A$. Similarly the mirror image of this equilibrium $(k<0)$ is also an equilibrium as long as $k \in[-A, 0]$. We can interpret this multiplicity as arising because any point in the interval can be identified as a median. The choice of a median then determines uniquely the entire distribution of returns.

Proof of Proposition 2. We begin by establishing the following Lemma:

Lemma 2. Consider a continutu of home types $i$ distributed along a line, and call $\left\|z_{i}\right\|$ type $i$ 's distance from the median. Similarly, consider a distribution of foreign types $i^{*} s$, with identical median, and call $\left\|z_{i^{*}}\right\|$ type $i^{*}$ 's distance from the median. A partnership can only be formed by $a$ home and a foreign type, and yields total profit $D z_{i i^{*}}$, where $z_{i j^{*}}$ is the Euclidean distance between the locations on the line of types $i$ and $i^{*}$ and $D$ is a positive constant. Then, if each individual is free to choose and bid for any matching partner, there exists an equilibrium where type $i$ 's return $r(i)$ equals $D\left\|z_{i}\right\|+k$, and type $i^{*}$ 's return $r\left(i^{*}\right)$ equals $D\left\|z_{i *}\right\|-k$. $k$ is such that no individual who strictly prefers matching to any available outside option is unable to find a partner. In addition, if the median is unique, individual returns in equilibrium must take this form.

Proof of Lemma 2. As in the case of Proposition 1, the first step in the proof requires showing that any equilibrium match must be formed by two partners on opposite sides of the median. The reasoning is identical to that given above, and we take the result as established in what follows.

We begin by proving that an equilibrium exists where all matched home types receive $D\left\|z_{i}\right\|+k$, and all matched foreign types $D\left\|z_{i^{*}}\right\|-k$. Consider types $i$ and $i^{*}$, from the home and foreign country respectively and on opposite sides of the median. Can either one of them do better? By demanding at least as much as they obtain in their current match, they cannot break up any of the existing partnerships. Since $k$ must be such that no individual who strictly prefers matching to the available outside options is unable to do so, there can be no possible partner currently unmatched who would be willing to receive less than in the candidate equilibrium. Thus neither $i$ nor $i^{*}$ can do better by matching with a type currently not matched. In addition, since $k$ must be such that no individual currently matched strictly prefers the outside option, $i$ and $i^{*}$ cannot do better by moving to the outside option. It follows that this is an equilibrium.

We now show that if the median is unique, no other equilibrium can exist. In any equilibrium, all types $i$ from the same country on the same side of the median (and matched with foreigners on the opposite side) must have returns $D\left\|z_{i}\right\|+k$, where $k$ is common to all of them: if this were not the case, the type with lowest $k$ could match with the current partner of a higher $k$ type, making both of them better off. In the equilibrium we have described, all types from the same country, on both sides of the median, face the same $k$. An alternative is plausible: All home types on the left of the median ("LHS types") receive $D\left\|z_{j}\right\|+k_{1}$, and all home types on the right of the median ("RHS types") receive $D\left\|z_{i}\right\|+k_{2}$ (and thus all RHS foreign types receive $D\left\|z_{i}\right\|-k_{1}$, and all LHS foreign types receive $D\left\|z_{i}\right\|-k_{2}$ ) where $k_{1}$ and $k_{2}$ are different. Suppose $k_{1}>k_{2}$. But then RHS 
home type $i$ could match with foreign type $i *$ immediately to the right of the median, and both would be better off. Thus this cannot be an equilibrium. The only possible equilibrium configuration is the one described in the Lemma.

Notice that to exclude this last scenario we have used the possibility of matches with individuals immediately next to the median. Thus we are ruling out a gap in the distribution of types in immediate proximity of the median, or equivalently, the existence of multiple medians. With a unique median, both the equilibrium configuration and, for each type, the distance from the median is uniquely defined. As discussed in the text, the only source of multiplicity left, in general, is the multiplicity of equilibrium $k$. The limit on the range of $k$ comes from the outside options available to the two groups. As stated in the lemma, in equilibrium it must be the case that no individual is excluded from matching against his will, since he would then have an incentive to insure himself a partner by offering a better deal to someone currently matched, and he could do so by altering $k$.

We now proceed with the proof of the Proposition. Suppose first that equilibrium wages are equal in the two countries. Then any two home producers on opposite sides of the median can assure themselves individual returns $D\left\|z_{i}\right\|, D\left\|z_{j}\right\|$ by returning to their domestic market and matching with each other (where $D=\pi(w)$ )--hence $k$ cannot be negative. But since the same option is available to foreign producers, $k$ cannot be positive. It follows that $k$ must be zero. Suppose now that the home wage is lower than the foreign wage. Then $D=\pi(w)$, where $w$ is now the home wage: foreigners matching internationally have the added bonus of gaining access to cheap labor, something that is not true for home producers. By the argument described above, $k$ cannot be negative. Suppose $k$ were zero. Then all foreign producers prefer to match internationally, and all home producers are indifferent. If all home producers match in the international market, this is where all transactions take place; but then all labor demand falls on home labor and in equilibrium $w^{*}$ cannot be higher than $w$. If only a portion of home producers chooses to match in the international market, then some foreign producers are rationed out of that market. It is in their interest to bid $k$ above zero and induce some home producers to switch partners. Thus $k$ cannot be zero. Suppose now that $k$ were positive. Now all home producers strictly prefer the international market. To avoid being rationed out of that market, they must bid $k$ down until all foreigners are induced to match internationally. But then again all transactions would take place in the international market, the demand for foreign labor would be zero, and the foreign equilibrium wage could not be above the home one. Thus $k$ cannot be positive. It follows that there is a unique equilibrium where $w$ equals $w^{*}$ and $k$ equals zero.

Proof of Corollary 1. As in the case of Proposition 1, the proof, originally in Casella and Rauch (1997), is reproduced here for convenience. Consider an equilibrium where the distribution of types returning to the domestic markets is symmetrical around zero. Suppose that returns to home types matching domestically are such that all $i$ 's $<0$ receive $\pi(w)\left|z_{i}\right|-k$ and all $i$ 's $>0$ $\pi(w)\left|z_{i}\right|+k(k>0)$. By Proposition 1 this can occur only if all types in $[-a, a](a \geq k)$ are absent from the domestic market, i.e., if they are successful with probability 1 in the international market 
and no-one else is. Consider producers $-a$ and $a$. Since they have the same probability of matching with any foreign type in the international market, and different expected returns in the domestic market, their probabilities of success cannot be equal. If the probability of success is 1 for $z_{i}=-a$ and less than 1 for all $z_{i}<-a$, then it must be less than 1 for $z_{i}=a$. This establishes the Corollary.

Proof of Proposition 7. If the distribution of types in the markets is symmetrical around zero, then the distributions of types from each country who choose to match through the group are also symmetrical around zero, or equivalently have median zero. The Proposition then follows directly from Lemma 2 if either there is no gap around zero in the distributions of types matching through the group, or if, in the presence of a gap, considering any other point in the gap as the relevant median leads to a violation of symmetry. In any symmetrical equilibrium, any gap in the distributions must be symmetrical around zero, and, in each country, types at equal distance from zero have identical expected returns in the markets. Consider a gap between $-a$ and $a$, and suppose that $b \in(0, a]$ is taken as the relevant median in calculating returns from group matchings. Then if $z_{j}=-a$ is just indifferent between matching through the group or in the international market, $z_{i}=a$ from the same country strictly prefers the market (and so, by continuity does $z_{i}=a+\epsilon, \epsilon>0$ ). Thus the gap cannot be symmetrical around zero, establishing the Proposition.

Proof of Proposition 9. Observe first that there is always an equilibrium where no-one uses the group ties (since an individual cannot deviate alone). Let us focus instead on the equilibrium with an active group. (i) It is easy to show that if wages are different there is no $k$ such that both $z_{i}=0$ and $z_{i^{*}}=0$ prefer (at least weakly) to match through the group than in the market. Thus all members using the ties cannot be an equilibrium. (ii) Consider two home types $z_{i}$ and $z_{s}$, with $z_{s}$ $>z_{i}$ and $z_{i}>0$. It is not difficult to verify that for any $z_{i^{*}}$ (and $\left.\psi<1\right),\left[r\left(i, i^{*}\right)-\left(\pi(w) z_{i}+k\right)\right] \geq$ $\left.\left[r\left(s, i^{*}\right)-\left(\pi(w) z_{s}\right)+k\right)\right]$, where $r\left(i, i^{*}\right)$ is the realized return to $z_{i}$ from matching with $z_{i^{*}}$ in the market and $\pi(w) z_{i}+k$ the return from matching through the group, both evaluated in the symmetrical equilibrium where all markets are active. (Notice that in verifying this statement we need to consider the four possible cases: $z_{i^{*}} \in S(i), S(s) ; z_{i^{*}} \in S(i), \notin S(s) ; z_{i^{*}} \notin S(i), \in S(s) ; z_{i^{*}} \notin$ $S(i), \notin S(S)$.) Because the inequality holds for any $z_{i^{*}}$, it must hold in expected values for any distribution of types in the market. Thus if $z_{i}$ prefers the ties to the market, so does $z_{s}$. By symmetry, the argument can be applied to $z_{i}<0$; thus more generally if $\left|z_{i}\right|$ prefers the ties to the market, so does $\left|z_{s}\right|>\left|z_{i}\right|$. It can be easily verified that the same logic holds in the foreign country. (iii) Points (i) and (ii) above establish that in any symmetrical equilibrium with an active group and unequal wages: a) not every member relies on the group; b) if $\left|z_{i}\right|\left(\left|z_{i^{*}}\right|\right)$ prefers the ties to the market, so does $\left|z_{s}\right|>\left|z_{i}\right|\left(\left|z_{s^{*}}\right|>\left|z_{i^{*}}\right|\right)$. Hence in the home country there must exist a positive number $\alpha\left(m, L / L^{*}\right)$ such that all members in $\left[-\alpha\left(m, L / L^{*}\right), \alpha\left(m, L / L^{*}\right)\right]$ prefer the market (at least weakly), and all members in $\left[-1,-\alpha\left(m, L / L^{*}\right)\right) \cup\left(\alpha\left(m, L / L^{*}\right), 1\right]$ prefer the ties (at least weakly). Similarly, in the foreign country there must exist an equivalent positive number $\alpha^{*}\left(m, L / L^{*}\right)$. In both countries, the equilibrium configuation is unique. (iv) Finally, since in equilibrium $k$ must be such that no producer who strictly prefers matching through the group is unable to do so, there must be an equilibrium where $\alpha=\alpha^{*}$. 
Solution of the model with group ties. The uneven withdrawal of group members from the anonymous international market changes the distribution of types faced by producers in that market. Since only $|z| \in(\alpha, 1]$ exploit their ties, the density of producers in the market $f(z)$ is no longer uniform, but is instead given by:

$$
f(z)=\begin{array}{ll}
\frac{1}{2-m(1-\alpha)} & |z| \in[0, \alpha] \\
\frac{2-m}{2[2-m(1-\alpha)]} & |z| \in(\alpha, 1]
\end{array}
$$

Computation of expected returns in the anonymous market (needed to solve for the equilibrium $\alpha$ ) and of labor demands requires use of (A1). The details are straightforward but tedious, and are available on request.

Proof of Proposition 10. We will prove that world income increases. It follows that world profits and world wages, which are fixed proportions of world income with a constant elasticity profit function, also increase. Denote the coefficients on $\pi^{\prime}(w)$ and $\pi^{\prime}\left(w^{*}\right)$ in the labor demand equations by $A$ and $A^{*}$, respectively. World income is then given by $A \pi(w)-w A \pi^{\prime}(w)+A^{*} \pi\left(w^{*}\right)$ $-w^{*} A^{*} \pi^{\prime}\left(w^{*}\right)$. Denoting the equilibria with and without group ties by subscripts 2 and 1 , respectively, the change in world income from the introduction of group ties is given by $A_{1}\left[\pi\left(w_{2}\right)-\pi\left(w_{1}\right)-\left(w_{2}-w_{1}\right) \pi^{\prime}\left(w_{1}\right)\right]+A_{1}^{*}\left[\pi\left(w_{2}^{*}\right)-\pi\left(w_{1}^{*}\right)-\left(w_{2}^{*}-w_{1}^{*}\right) \pi^{\prime}\left(w_{1}^{*}\right)\right]+\left(A_{2}-A_{1}\right) \pi\left(w_{2}\right)+$ $\left(A_{2}^{*}-A_{1}^{*}\right) \pi\left(w_{2}^{*}\right)$. The two terms in brackets are non-negative (positive if wages change) because $\pi$ is a convex function of $w$. Since $w_{2}<w_{2}^{*}$, sufficient conditions for world income to increase are therefore $A_{2}-A_{1}>0$ and $\left(A_{2}+A_{2}^{*}\right)-\left(A_{1}+A_{1}^{*}\right) \geq 0$, representing transfer of labor demand from the high- to the low-wage country. Using equation (A1) above we can compute $A(\psi, \alpha ; m)$ and $A^{*}(\psi, \alpha, m)$ for a NIE with ties and compare these to $A(\Psi)$ and $A^{*}(\psi)$ from $(11)$ and $\left(11^{*}\right)$, respectively. Holding $\psi$ constant across the equilibria with and without ties, it is straightforward to show that, for any $m \in(0,2)$ and for any $\psi, \alpha \in(0,1), A(\psi, \alpha ; m)>A(\psi)$ and $A(\psi, \alpha ; m)+$ $A^{*}(\psi, \alpha ; m) \geq A(\psi)+A^{*}(\psi)$. Suppose $\psi$ is greater in the NIE with ties. The increase in $\psi$ can be shown to increase $A(\psi, \alpha ; m)+A^{*}(\psi, \alpha ; m)$ (fewer bad matches are concluded, hence the sum of $z_{i j}$ over all producers goes up) so $\left(A_{2}+A_{2}^{*}\right)-\left(A_{1}+A_{1}^{*}\right) \geq 0$ must hold, but decrease $A(\Psi, \alpha ; m)$. However, if $A_{2}-A_{1} \leq 0$ then we must have $\psi_{2} \leq \psi_{1}$, contradicting the increase in $\psi$. If on the other hand $\psi$ is smaller in the NIE with ties, $A_{2}-A_{1}>0$ must hold, so if $\left(A_{2}+A_{2}^{*}\right)-\left(A_{1}+A_{1}^{*}\right)<0$ we must have $\psi_{2}>\psi_{1}$, contradicting the decrease in $\Psi$.

Proof of Proposition 11. For the first part of the proposition, note that an IE maximizes the world profits of the uniformly distributed set of producers of mass 4 , hence it also maximizes the world profits of the nonmember producers, who constitute a uniformly distributed subset of producers of mass $4-2 m$. Consider the case where an IE obtains for $m$ satisfying $(6+m) /(2-m)=$ 
$L / L^{*}$. By continuity there exists an $\bar{m}$ just below this level for which an NIE obtains and world profits of nonmember producers are higher than in the NIE that obtains in the absence of group ties. Now consider the case where only an NIE obtains for $m$ satisfying $(6+m) /(2-m)=L / L^{*}$. It is easy to show that an IE must obtain for $m$ sufficiently above this level. The above argument can then be repeated. The simulations cited in footnote 17 in the text prove the second part of the proposition.

Proof of Proposition 12. It follows from Proposition 7 that the return to matching within the group is given by $z_{i} \pi\left(w^{2}\right)+(-) k$ for any country $2(1)$ group member with $z_{i}>0$. This must be compared with the return from matching outside the group, i.e., the expected return from matching with a producer from country 3 . Since countries 1 and 2 both have (weakly) higher wages than country 3 , this expectation is computed using the acceptance set $S^{*}\left(i^{*}\right)$ given by equation $\left(7^{*}\right)$. Under the baseline solution any producer from country 1 or 2 faces a uniform distribution of country 3 producers (note the contrast with the model of section V and (A1)). Using this fact yields

$$
\begin{aligned}
& \operatorname{Er}^{1}(i)=\left(\pi\left(w^{3}\right) / 16\right) z_{i}\left[4+z_{i}\left(-1+\psi^{1}\right)^{2}+12 \psi^{1}\right] \\
& \operatorname{Er}^{2}(i)=\left(\pi\left(w^{3}\right) / 16\right) z_{i}\left[4+z_{i}\left(-1+\psi^{2}\right)^{2}+12 \psi^{2}\right] .
\end{aligned}
$$

It is easy to show that $\psi^{1}<\psi^{2}$ implies $E r^{1}(i)<E r^{2}(i) \forall z_{i}>0$.

i) $\psi^{2}=1$ implies $w^{2}=w^{3}$. This yields $E r^{2}(i)=z_{i} \pi\left(w^{2}\right)$, so that all group members in country 2 strictly prefer to use their ties for any $k>0$. In country 1 , however, group members in the neighborhood of zero prefer the market for any $k>0$. Rationed country 2 producers will bargain $k$ down to zero and in equilibrium all group members in both countries use their ties.

ii) $E r^{1}(i)>z_{i} \pi\left(w^{2}\right) \forall z_{i}>0$ is sufficient to rule out any use of the group ties since $k \geq 0$. Using (A2), this reduces to $\left[4+z_{i}\left(-1+\psi^{1}\right)^{2}+12 \psi^{1}\right] / 16>\psi^{2} \forall z_{i}>0$, and further to $\left(1+3 \psi^{1}\right) / 4>\psi^{2}$. Note that this condition cannot be satisfied for $\psi^{2}=1$.

iii) With $\psi^{2}<1$ it is easily shown that no group members in country 2 will use their ties unless $k>0$, and that for $k>0$ there exists at most one value of $z_{i}$ for which $\operatorname{Er}^{2}(i)=z_{i} \pi\left(w^{2}\right)+k$.

Considering $z_{i}=0$, we see that the group return must intersect the market return from above. Using (A2), it is also easily shown that a sufficient condition for the equation $\operatorname{Er}^{1}(i)=z_{i} \pi\left(w^{2}\right)-k$ to have at most one solution is $(1 / 8)\left[2+z_{i}\left(-1+\psi^{1}\right)^{2}+6 \psi^{1}\right]<\psi^{2} \forall z_{i}>0$, i.e., that the market return always increases more slowly with $z_{i}$ than the group return so that the latter can only intersect the former from below. This sufficient condition reduces to $\left(1+\psi^{1}\right)\left(3+\psi^{1}\right) / 8<\psi^{2}$. In equilibrium $k$ will adjust to equate the masses of group members that prefer the ties in countries 1 and 2. Denote the value of $z_{i}$ above (below) which all group members in country 1 (2) prefer the ties by $\alpha(\beta)$. The share of group members that prefers the ties is then given by $1-\alpha(\beta)$ in country $1(2)$, so that in equilibrium we must have $\beta=1-\alpha$. To complete the proof we must therefore show that there exists a unique $\alpha \in(0,1)$ that solves the following three equations: 


$$
\begin{aligned}
& (1 / 16) \alpha\left[4+\alpha\left(-1+\psi^{1}\right)^{2}+12 \psi^{1}\right]=\alpha \psi^{2}-\kappa \\
& (1 / 16) \beta\left[4+\beta\left(-1+\psi^{2}\right)^{2}+12 \psi^{2}\right]=\beta \psi^{2}+\kappa \\
& \beta=1-\alpha,
\end{aligned}
$$

where $\kappa \equiv k / \pi\left(w^{3}\right)$. By eliminating $\beta$ and $\kappa$ from (A3) it is easy to show that we obtain a quadratic equation in $\alpha$, which is easily shown to have one and only one root in the interval $(0,1)$ given $\psi^{1}<1$ and $\left(1+\psi^{1}\right)\left(3+\psi^{1}\right) / 8<\psi^{2}<1$. It is also easy to show that this root is decreasing in $\psi^{2}$ and increasing in $\psi^{1}$. 